\title{
Long-term Remission of Primary Gastric T Cell Lymphoma Associated with Human T Lymphotropic Virus Type 1: A Report of Two Cases and Review of the Literature
}

\author{
Keiichi Tanaka ${ }^{1,2}$, Shotaro Nakamura ${ }^{1}$, Takayuki Matsumoto ${ }^{1}$, Katsuya Hirakawa ${ }^{1,2}$, \\ Ritsuko Yanaru-Fujisawa ${ }^{1}$, Kaoru Onoyama ${ }^{2}$, Hisanobu Sakata ${ }^{2}$, Koichi Ohshima ${ }^{3}$, \\ Takashi $\mathrm{Yao}^{4}$ and Mitsuo Iida ${ }^{1}$
}

\begin{abstract}
Two cases of primary gastric T-cell lymphoma associated with human T lymphotropic virus type 1 (HTLV1) are presented. Case 1 was a 54-year-old man who had multiple ulcerating tumors in the lower corpus and gastric antrum. Case 2, a 60-year-old man, showed a large ulcerating tumor in the upper corpus. Both patients were positive for serum anti-HTLV-1 antibody and for the monoclonal integration of HTLV-1 proviral DNA in the tumor cells by Southern blot analysis. The patients were thus diagnosed as having primary gastric T-cell lymphoma associated with HTLV-1 of stage $\mathrm{II}_{1}$. Case 1 underwent total gastrectomy followed by chemotherapy, while Case 2 was treated by chemotherapy and radiotherapy. Both patients have been in complete remission for more than 4 years (96 months in Case 1 and 50 months in Case 2) after the treatments. Although primary gastric T-cell lymphomas associated with HTLV-1 is characterized by an extremely poor prognosis, the present cases suggest that in the early stage, long-term survival can possibly be achieved with appropriate treatments.
\end{abstract}

Key words: adult T-cell leukemia/lymphoma, primary gastric lymphoma, prognosis

(DOI: 10.2169/internalmedicine.46.0323)

\section{Introduction}

Most primary gastric lymphomas are of B-cell origin, and T-cell lymphomas have been shown to be rare $(1,2)$. While systemic adult T-cell leukemia or lymphoma (ATLL), which are caused by human T lymphotropic virus type 1 (HTLV$1)$, often involves the gastrointestinal tract $(3,4)$, primary gastric T-cell lymphoma associated with HTLV-1 is extremely rare (5-18). In addition, primary gastric T-cell lymphomas, especially those associated with HTLV-1, generally show an extremely poor prognosis (19). We herein report two cases of primary gastric T-cell lymphoma associated with HTLV-1, also referred to as primary gastric ATLL, both of which were successfully treated with a combination of chemotherapy and either surgical resection or radiotherapy (RT).

\section{Case Report}

\section{Case 1}

A 54-year-old Japanese man was admitted to Nippon Steel Yawata Memorial Hospital due to epigastric pain in May 1998. Upper gastrointestinal endoscopy demonstrated multiple ulcerating tumors mimicking type 2 advanced cancers on the lesser curvature of the lower corpus, the posterior wall of the angularis, and the anterior wall of the antrum (Fig. 1). In addition, various-sized multiple nodular lesions with central depression or ulceration and diffusely

\footnotetext{
${ }^{1}$ Department of Medicine and Clinical Science, Graduate School of Medical Sciences, Kyushu University, Fukuoka, ${ }^{2}$ Department of Gastroenterology, Nippon Steel Yawata Memorial Hospital, Kitakyushu, ${ }^{3}$ First Department of Pathology, School of Medicine, Fukuoka University, Fukuoka and ${ }^{4}$ Department of Anatomic Pathology, Graduate School of Medical Sciences, Kyushu University, Fukuoka Received for publication May 19, 2007; Accepted for publication July 19, 2007 Correspondence to Dr. Keiichi Tanaka, k-ichi@intmed2.med.kyushu-u.ac.jp
} 


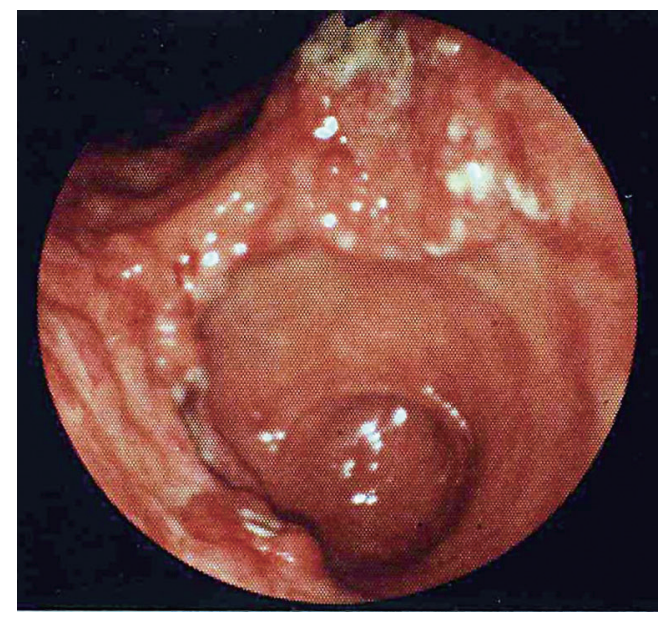

Figure 1. Case 1. Esophagogastroduodenoscopic view of gastric lesions. Multiple ulcerating tumors mimicking type 2 advanced gastric cancers are observed on the lesser curvature of the lower corpus, the posterior wall of the angularis, and the anterior wall of the antrum.

thickened mucosa were observed in the upper corpus. Biopsied specimens obtained from all these lesions revealed diffuse infiltration of CD3-positive atypical lymphocytes, suggesting a diagnosis of malignant lymphoma of the T-cell type. Peripheral leukocytes were determined to present at $8200 / \mu \mathrm{L}$ without any atypical lymphocytes. While serum levels of lactate dehydrogenase (LDH, 295 IU/L) and calcium $(8.7 \mathrm{mg} / \mathrm{mL})$ were normal, soluble interleukin-2 receptor (sIL-2R) was elevated to $1165 \mathrm{U} / \mathrm{ml}$ (normal range; 220 530). His serum was positive for anti-HTLV-1 antibody. Colonoscopy, small bowel follow-through, bone marrow aspiration and biopsy, computerized tomography (CT) of the chest and abdomen, and gallium scintigraphy showed no abnormalities. Total gastrectomy with splenectomy was performed in May 1998.

Histologic examination of the resected specimen revealed that the tumor cells had involved the whole thickness of the gastric wall (Fig. 2a). Immunohistochemically, the cells were positive for CD2, CD3, CD4, CD5, CD25, CD30, CD 43, and CD45RO (Fig. 2b), but negative for CD7, CD8, CD 19, CD20, CD56, CD57, and TIA-1. Southern blot analysis of the frozen samples from the gastric tumor demonstrated the presence of HTLV-1 proviral DNA, but the analysis of those from peripheral blood was negative for the DNA (Fig. 3). Polymerase chain reaction (PCR) for HTLV-1 pX Tax gene showed a positive result in the gastric lesion and in the peripheral blood. Another PCR for T-cell receptor genes showed that the tumor cells had monoclonal rearrangement of the T-cell receptor $\beta \mathrm{F}-1$ gene, but rearrangement of the T-cell receptor $\delta 1$ gene was not discerned.

The infiltration of lymphoma cells was found in the perigastric lymph nodes. Thus, the patient was diagnosed as having primary gastric ATLL of stage $\mathrm{II}_{1}$. Subsequently, the patient was treated using six courses of multi-agent chemotherapy with pirarubicin, cyclophosphamide, etoposide, and

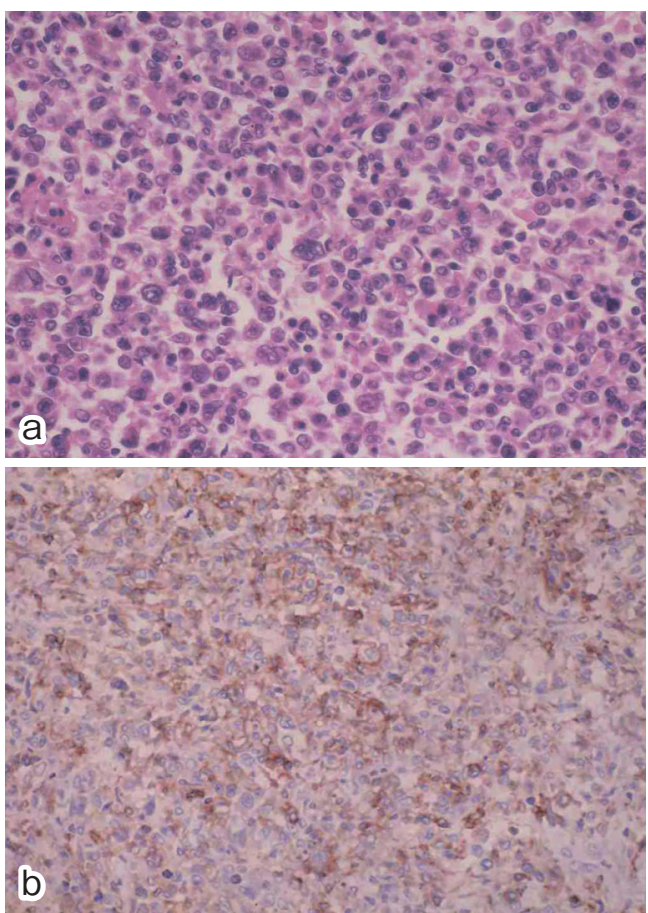

Figure 2. Case 1. Histologic pictures of the gastric lesions from the resected specimens $(\times 100)$. a $\mathrm{A}$ high-power view of hematoxylin and eosin staining shows a diffuse proliferation of large atypical lymphoid cells with indented or irregular nuclei, indistinct nucleoli, and abundant pale or slightly eosinophilic cytoplasm. b Immunohistochemical staining reveals neoplastic cells to be positive for CD45RO.

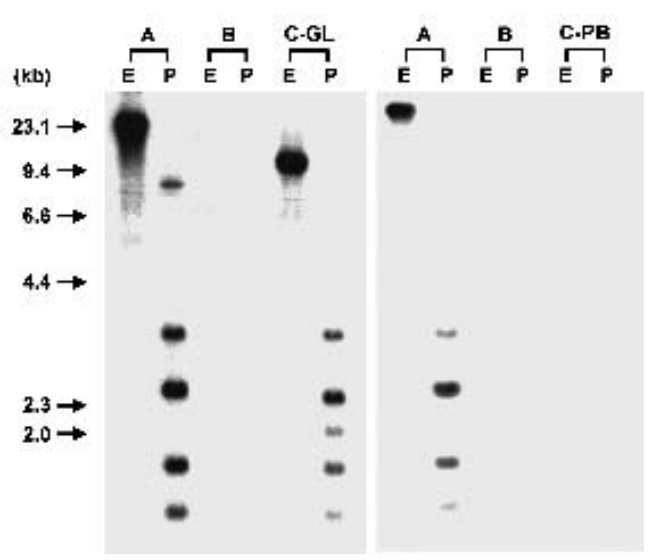

Figure 3. Case 1. Southern blot analysis using a full-length HTLV-1 probe shows the monoclonal integration of HTLV-1 proviral DNA in the samples from the gastric tumor, but the analysis of those from peripheral blood was negative for the DNA. A, positive control of HTLV-1 monoclonal DNA; B, negative control (human placental DNA); C-GL, DNA extracted from gastric lesion; C-PB, DNA extracted from peripheral blood; E, EcoRI digestion; P, PstI digestion.

prednisolone. Follow-up examinations including laboratory tests, CT, and gallium scintigraphy after the chemotherapy showed no relapse of the lymphoma. The patient has been alive and well without any evidence of lymphoma 8 years 

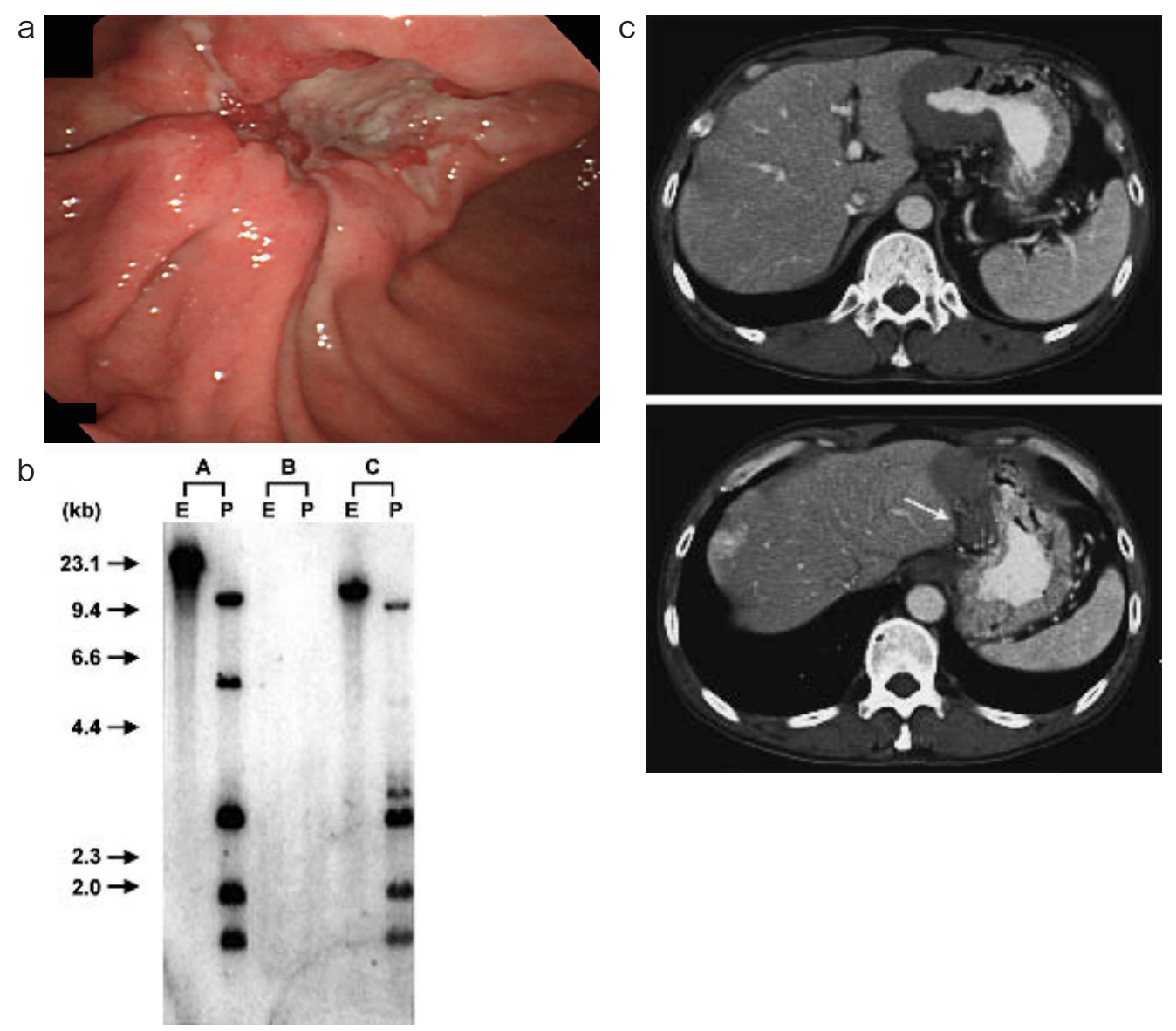

Figure 4. Case 2. a Esophagogastroduodenoscopic view at the time of the initial examination. A large ulcerating tumor can be seen on the anterior wall to the lesser curvature of the lower corpus. b Southern blot analysis using a full-length HTLV-1 probe shows the monoclonal integration of HTLV-1 proviral DNA in the samples from the gastric tumor. A, positive control of HTLV-1 monoclonal DNA; B, negative control (human placental DNA); C, DNA extracted from gastric lesion; E, EcoRI digestion; P, Pst I digestion. c Abdominal CT revealed thickening of the gastric wall and multiple perigastric lymphadenopathy (arrow).

after surgery.

\section{Case 2}

A 60-year-old Japanese man was admitted to Kyushu University Hospital due to epigastric pain in March 2002. Upper gastrointestinal endoscopy revealed a large ulcerating tumor on the anterior wall to the lesser curvature of the lower corpus (Fig. 4a). Endoscopic ultrasonography demonstrated the tumor to have invaded the entire thickness of the gastric wall and enlarged perigastric lymph nodes. Biopsy revealed a proliferation of large atypical lymphoid cells that were immunohistochemically positive for CD3 and CD45 RO, but negative for CD20 and CD79a. Based on these histologic findings, a diagnosis of malignant lymphoma of the T-cell phenotype was made. Southern blot analysis detected the monoclonal integration of HTLV-1 proviral DNA in the frozen biopsied specimens taken by gastric biopsy (Fig. 4b). The peripheral leukocyte count was $4,680 / \mu \mathrm{L}$ without any atypical lymphocytes. Although serum levels of LDH (172 IU/L) and calcium $(8.1 \mathrm{mg} / \mathrm{mL})$ were within normal ranges, sIL-2R was elevated to $4,090 \mathrm{U} / \mathrm{ml}$. The serum anti-HTLV-1 antibody was positive. Colonoscopy, small bowel followthrough, bone marrow aspiration and biopsy, and CT of the chest showed no abnormalities. However, abdominal CT revealed multiple perigastric lymphadenopathy in addition to thickening of the gastric wall (Fig. 4c). Fluorine-18 fluorodeoxyglucose positron emission tomography (FDG-PET) showed abnormal uptake in the stomach and perigastric lymph nodes. Thus, the patient was diagnosed as having primary gastric ATLL of stage $\mathrm{II}_{1}$.

The patient was treated using six courses of multi-agent chemotherapy with a regimen of cyclophosphamide, doxorubicin, vincristine, and prednisolone, followed by RT of 40.5 Gy. Follow-up endoscopy revealed a marked regression of the gastric tumor and no evidence of lymphoma was recognized by gastric biopsy, CT, or FDG-PET. The patient was followed up with oral etoposide at $50 \mathrm{mg} /$ day for the first 21 days, and has been alive without any evidence of relapse for 50 months after the start of the initial treatment. 
Table 1. Summary of Primary Gastric T-cell Lymphoma Associated with HTLV-1 in the Literature

\begin{tabular}{|c|c|c|c|c|c|c|c|c|c|c|c|c|}
\hline No. & Author (year) & Age & Gender & $\begin{array}{l}\text { HTLV-1 } \\
\text { antibody }\end{array}$ & $\begin{array}{l}\text { HTLV-1 } \\
\text { proviral DNA }\end{array}$ & $\begin{array}{l}\text { Leukocyte } \\
(/ \mu \mathrm{L})\end{array}$ & $\begin{array}{l}\text { Atyp.ly } \\
(\%)\end{array}$ & $\begin{array}{l}\text { High } \\
\text { LDH }\end{array}$ & $\begin{array}{l}\text { Hyper- } \\
\text { calcemia }\end{array}$ & Stage $^{\mathrm{b}}$ & Treatment & Prognosis \\
\hline 1 & Kubonishi (1987) & 41 & $\mathrm{~F}$ & + & + & 9200 & 3 & ND & - & $\mathrm{II}_{1}$ & $\mathrm{~S}+\mathrm{RT}+\mathrm{Ch}$ & 9 mo, alive \\
\hline 2 & Nakamura (1991) & 44 & M & + & ND & 8700 & 10 & + & - & IV & $\mathrm{Ch}$ & $8 \mathrm{mo}, \mathrm{DD}$ \\
\hline 3 & Nakamura (1991) & 58 & M & + & ND & 11300 & 2 & - & - & IV & ND & ND \\
\hline 4 & Shimamoto (1991) & 69 & $\mathrm{~F}$ & + & ND & 2600 & 0 & + & - & I & $\mathrm{Ch}+\mathrm{S}$ & $8 \mathrm{mo}$, died \\
\hline 5 & Kojima (1992) & 42 & $\mathrm{~F}$ & + & + & 12100 & 0 & + & - & I & $\mathrm{S}+\mathrm{Ch}$ & $31 \mathrm{mo}$, alive \\
\hline 6 & Katabami (1992) & 53 & F & + & ND & 7400 & 0 & - & - & I & $\mathrm{Ch}$ & $1 \mathrm{mo}$, alive \\
\hline 7 & Tokioka (1993) & 41 & $\mathrm{~F}$ & + & + & ND & $1-2$ & ND & ND & IV & $\mathrm{Ch}$ & $11 \mathrm{mo}, \mathrm{DD}$ \\
\hline 8 & Tokioka (1993) & 69 & $\mathrm{~F}$ & + & + & ND & ND & ND & ND & $\mathrm{II}_{1}$ & $\mathrm{Ch}+\mathrm{S}$ & $15 \mathrm{mo}, \mathrm{DD}$ \\
\hline 9 & Tokioka (1993) & 44 & M & + & + & 13300 & 5 & ND & ND & IV & $\mathrm{Ch}$ & $16 \mathrm{mo}, \mathrm{DD}$ \\
\hline 10 & Tokunaga (1993) & 49 & M & + & + & 5600 & 0 & + & - & $\mathrm{II}_{1}$ & ND & $12 \mathrm{mo}, \mathrm{DD}$ \\
\hline 11 & Tokunaga (1993) & 59 & M & ND & + & 4100 & 0 & - & ND & $\mathrm{II}_{1}$ & ND & $1 \mathrm{mo}$, died \\
\hline 12 & Tokunaga (1993) & 70 & F & + & + & 7900 & 0 & + & - & $\mathrm{II}_{1}$ & ND & $16 \mathrm{mo}, \mathrm{DD}$ \\
\hline 13 & Yatabe (1994) & 59 & M & + & + & ND & 0 & ND & ND & III & $\mathrm{Ch}+\mathrm{S}$ & $10 \mathrm{mo}, \mathrm{DD}$ \\
\hline 14 & Takimoto (1994) & 29 & M & + & + & 14600 & 0 & + & ND & $\mathrm{II}_{1}$ & $\mathrm{Ch}$ & $24 \mathrm{mo}, \mathrm{DD}$ \\
\hline 15 & Hiroyasu (1996) & 52 & $\mathrm{~F}$ & + & ND & Normal & 0 & + & ND & IIE & $\mathrm{Ch}+\mathrm{Surg}$ & $5 \mathrm{mo}, \mathrm{DD}$ \\
\hline 16 & Shimada (1997) & 73 & $\mathrm{~F}$ & + & + & 6700 & 0 & ND & ND & ND & ND & $21 \mathrm{mo}$, died \\
\hline 17 & Shimada (1997) & 44 & $\mathrm{~F}$ & + & + & 4900 & 0 & ND & ND & ND & ND & $39 \mathrm{mo}, \mathrm{DD}$ \\
\hline 18 & Nozoe (2000) & 65 & M & + & + & 7980 & ND & + & - & $\mathrm{II}_{1}$ & $\mathrm{~S}+\mathrm{Ch}$ & $3 \mathrm{mo}, \mathrm{DD}$ \\
\hline 19 & Katoh (2000) & 58 & M & ND & + & ND & ND & ND & ND & III & $\mathrm{S}+\mathrm{Ch}$ & $14 \mathrm{mo}$, died \\
\hline 20 & Sakata (2001) & 55 & M & + & + & ND & 0 & ND & ND & I & $\mathrm{S}$ & 11 years, alive \\
\hline 21 & Sakata (2001) & 68 & F & + & + & ND & 0 & + & ND & I & $\mathrm{S}+\mathrm{Ch}$ & $20 \mathrm{mo}, \mathrm{DD}$ \\
\hline 22 & Sakata (2001) & 63 & $\mathrm{~F}$ & + & + & ND & 0 & + & ND & $\mathrm{II}_{1}$ & $\mathrm{Ch}+\mathrm{S}$ & ND \\
\hline 23 & Present case 1 & 54 & M & + & + & 8200 & 0 & - & - & $\mathrm{II}_{1}$ & $\mathrm{~S}+\mathrm{Ch}$ & 8 years, alive \\
\hline 24 & Present case 2 & 60 & M & + & + & 4680 & 0 & - & - & $\mathrm{II}_{1}$ & $\mathrm{Ch}+\mathrm{RT}$ & $50 \mathrm{mo}$, alive \\
\hline
\end{tabular}

Atyp.ly, atypical lymphocyte; ND, not described; S, surgery; RT, radiotherapy; Ch, chemotherapy; mo, months; DD, Died of disease.

${ }^{a}$ Detected in the gastric lesions. ${ }^{b}$ Lugano International Conference classification (20).

\section{Discussion}

Most cases with lymphomatous variant of ATLL are in the advanced stage with prominent lymphadenopathy and/or multiple visceral involvement. Thus, primary ATLL arising in the stomach is extremely rare. Sakata et al (18) have proposed criteria for ATLL restricted to the stomach (stage I or $\mathrm{II}_{1}$ ) as follows: 1) positive for serum anti-HTLV-1 antibody; 2) positive for specific T-cell markers in the gastric tumor cells; 3) positive for HTLV-1 proviral DNA only in the gastric tumor cells, and not in other organs or peripheral blood by Southern blotting; 4) an absence of abnormal lymphocytes or HTLV-1 proviral DNA in the peripheral blood and bone marrow. The present Case 1 fulfilled these criteria, while we did not confirm absence of HTLV-1 proviral DNA in the peripheral blood in Case 2 .

To date, 22 cases of primary gastric T-cell lymphoma associated with HTLV-1 have been reported in the English literature (5-18). Table 1 summarizes the clinicopathologic features of these 22 cases and the present 2 cases. All cases satisfied the criteria for primary gastric lymphoma as defined by Lewin et al (20), though some did not fulfill the criteria for ATLL restricted to the stomach as defined by Sakata et al (18). There were 12 men and 12 women, with ages ranging from 29 to 73 years (median, 56.5 years). Serum anti-HTLV-1 antibody was positive in 22 cases (92\%), and monoclonal integration of HTLV-1 proviral DNA in the gastric tumor was confirmed in 19 cases (79\%). According to the Lugano International Conference classification for clinical staging of gastrointestinal lymphoma (21), 5 cases were at stage $\mathrm{I}, 10$ at stage $\mathrm{II}_{1}, 1$ at stage $\mathrm{IIE}$, and 6 at stage IV, while the stage was not specified in the remaining 2 cases. Ten cases were treated by a combination of surgical resection and chemotherapy, 5 patients were treated by chemotherapy alone, 1 by surgical resection alone, and 1 by chemotherapy plus RT, while 1 patient underwent surgical resection plus RT and chemotherapy.

Follow-up data were available in 22 patients. At the time of the last follow-up, 16 patients $(73 \%)$ had died, while 6 $(27 \%)$ were alive. The median survival period was 14.5 months. Kaplan-Meier analysis revealed 2- and 5-year survival probabilities to be $26 \%$ and $19 \%$, respectively. These survival data were similar to those of a common lymphomatous variant of ATLL (22). A log-rank test revealed the clinical stage to be the only significant variable associated with the prognosis. Patients with stage $\mathrm{I}_{\text {or }} \mathrm{II}_{1}$ disease $(\mathrm{n}=$ 14) showed a significantly better survival than those with stage IIE or IV $(n=6)$; 2-year survival probabilities were $34 \%$ and $0 \%$, respectively (log-rank test, $\mathrm{p}=0.031$,). Other 
factors including age, gender, leukocytosis, atypical lymphocytes, or elevation of LDH did not significantly affect the prognosis. It has been demonstrated that the stage is the major prognostic factor for primary gastrointestinal lymphoma (23). Based on these findings, we consider that some patients in the early stage (stage $\mathrm{I}$ or $\mathrm{II}_{1}$ ), such as the present cases, possibly show better survivals when an appropriate treatment is applied. At present, a combination of systemic chemotherapy plus local treatment (radical resection or RT) seems to be an optimal strategy for localized gastric T-cell lymphoma.

\section{References}

1. Nakamura S, Akazawa K, Yao T, Tsuneyoshi M. Primary gastric lymphoma: a clinicopathologic study of 233 cases with special reference to evaluation with the MIB-1 index. Cancer 76: 13131324, 1995.

2. Isaacson PG. Gastrointestinal lymphoma. Hum Pathol 25: 10201029, 1994.

3. Utsunomiya A, Hanada S, Terada A, et al. Adult T-cell leukemia with leukemia cell infiltration into the gastrointestinal tract. Cancer 61: 824-828, 1988.

4. Obata S, Matsuzaki H, Nishimura H, Kawakita M, Takatsuki K. Gastroduodenal complications in patients with adult T-cell leukemia. Jpn J Clin Oncol 18: 335-342, 1988.

5. Kubonishi I, Daibata M, Yano S, Fujishita M, Taguchi H, Miyoshi I. Gastric lymphoma associated with human T-cell leukemia virus type I. Arch Intern Med 147: 603-605, 1987.

6. Nakamura S, Iida M, Matsui T, et al. Adult T-cell leukemia/lymphoma with gastric lesions: report of three cases. J Clin Gastroenterol 13: 390-394, 1991.

7. Shimamoto Y, Yamaguchi M, Tokunaga O, Nagumo F, Tadano J. Primary extranodal lymphoma caused by HTLV-I. Br J Haematol 78: 126-128, 1991.

8. Katabami S, Hinoda Y, Ohe Y, et al. Adult T-cell leukemia/lymphoma (lymphoma type) with remarkable gastric lesions: a case report. Gastroenterol Jpn 27: 95-101, 1992.

9. Kojima H, Ikeda H, Kubo T, et al. HTLV-I associated gastric lymphoma. Zentralbl Pathol 138: 351-354, 1992.

10. Tokioka T, Shimamoto Y, Tokunaga O, Yamaguchi M. HTLV-I associated and non-associated primary T-cell lymphoma of gastrointestinal tract. Leuk Lymphoma 9: 399-405, 1993.

11. Tokunaga O, Watanabe T, Shimamoto Y, Tokudome S. Primary Tcell lymphoma of the gastrointestinal tract associated with human T-cell lymphotropic virus type I: an analysis using in situ hybridization and polymerase chain reaction. Cancer 71: 708-716, 1993.

12. Yatabe $Y$, Mori N, Oka K, Nakazawa M, Asai J. Primary gastric T-cell lymphoma: morphological and immunohistochemical studies of two cases. Arch Pathol Lab Med 118: 547-550, 1994.

13. Takimoto $Y$, Tanaka H, Tanabe O, Kuramoto A, Sasaki N, Nanba
K. A patient with anaplastic large cell lymphoma (Ki-1 lymphoma) showing clonal integration of HTLV-1 proviral DNA. Leukemia 8: 507-509, 1994.

14. Hiroyasu S, Shiraishi M, Shimabukuro M, Kusano T, Muto Y. Adult T-cell leukemia/lymphoma with a giant gastric tumor: a case report. Jpn J Clin Oncol 26: 374-378, 1996.

15. Shimada-Hiratsuka M, Fukayama M, Hayashi Y, et al. Primary gastric T-cell lymphoma with and without human T-lymphotropic virus type 1. Cancer 80: 292-303, 1997.

16. Nozoe T, Matsumata T. Primary gastric lymphoma associated with human T-cell leukaemia virus I. Eur J Gastroenterol Hepatol 12: 357-360, 2000.

17. Katoh A, Ohshima K, Kanda M, et al. Gastrointestinal T cell lymphoma: predominant cytotoxic phenotypes, including alpha/beta, gamma/delta $\mathrm{T}$ cell and natural killer cells. Leuk Lymphoma 39: 97-111, 2000.

18. Sakata H, Iwakiri R, Koyama T, et al. Human T-cell lymphotropic virus-associated primary gastric lymphoma. Dig Dis Sci 46: 13811386, 2001.

19. Horie R, Yatomi Y, Wakabayashi T, et al. Primary gastric T-cell lymphomas: report of two cases and a review of the literature. Jpn J Clin Oncol 29: 171-178, 1999.

20. Lewin KJ, Ranchod M, Dorfman RF. Lymphomas of the gastrointestinal tract: a study of 117 cases presenting with gastrointestinal disease. Cancer 42: 693-707, 1978.

21. Rohatiner A, d'Amore F, Coiffier B, et al. Report on a workshop convened to discuss the pathological and staging classifications of gastrointestinal tract lymphoma. Ann Oncol 5: 397-400, 1994.

22. Shimoyama M. Diagnostic criteria and classification of clinical subtypes of adult T-cell leukaemia-lymphoma: a report from the Lymphoma Study Group (1984-87). Br J Haematol 79: 428-437, 1991.

23. Nakamura S, Matsumoto $T$, Iida M, Yao $T$, Tsuneyoshi M. Primary gastrointestinal lymphoma in Japan: a clinicopathologic analysis of 455 patients with special reference to its time trends. Cancer 97: 2462-2473, 2003.

(C) 2007 The Japanese Society of Internal Medicine http://www.naika.or.jp/imindex.html 